\title{
Nilai Religiositas Pupuh Kasmaran dalam Lontar Yusuf dan Relevansinya dengan Kehidupan di Era Disruptif
}

\author{
Martina Pupita Rakhmia,1* \\ a Universitas Negeri Semarang, Jalan Kelud Utara III, Semarang, Indonesia, 50237 \\ ${ }^{1}$ martinapuspita@gmail.com
}

* Corresponding Author

\begin{tabular}{ll}
\hline INFO ARTIKEL & ABSTRAK \\
\hline Sejarah Artikel: & Keberadaan sastra daerah memiliki beragam fungsi. Salah satunya sebagai \\
Diterima: 28 Maret 2020 & penyebar ajaran agama. Banyuwangi merupakan salah satu daerah yang \\
Direvisi: 29 Maret 2020 & memanfaatkan sastra daerah sebagai penyebaran ajaran agama Islam, \\
Disetujui: 10 April 2020 & melalui Lontar Yusup Banyuwangi. Dalam Lontar Yusup Banyuwangi, nilai \\
Tersedia Daring: 12 April & $\begin{array}{l}\text { religiositas adalah yang paling dominan. Untuk itu, dalam penelitian ini } \\
\text { dikaji nilai-nilai religiositas dengan memfokuskan pengkajian pada Pupuh }\end{array}$ \\
2020 & Kasmaran. Selain itu juga dibahas relevansi nilai religiositas dengan \\
\hline Kata Kunci: & kehidupan di era disruptif. Teknik pengumpulan data melalui studi \\
Pupuh kasmaran & dokumen. Data dianalisis dengan metode analisis-deskriptif. Dari hasil \\
Era disruptif & penelitian diketahui terdapat empat nilai religiositas: (1) keimanan \\
& terhadap Tuhan, (2) keteringatan manusia terhadap sifat Tuhan, (3) \\
& ketaatan manusia terhadap Tuhan dan (4) kepasrahan manusia terhadap \\
& Tuhan, serta empat dimensi religiositas: dimensi praktis, dimensi ideologis, \\
& dimensi pengetahuan, dan dimensi perasaan. (2) nilai religiositas pada \\
& Pupuh Kasmaran sangat relevan dalam kehidupan manusia di era disruptif.
\end{tabular}

\begin{tabular}{ll}
\hline ABSTRACT \\
\hline Keywords: & The existence of regional literature has a variety of functions. One of them is \\
Religious values & as the spread of religious teachings. Banyuwangi is an area that utilizes \\
Pupuh kasmaran & regional literature as the spread of Islamic teachings, namely through Lontar \\
Disruptive era & Yusup Banyuwangi. In Lontar Yusup Banyuwangi, the value of religiosity is the \\
& most dominant. For this reason, this study examine the values of religiosity by \\
& focusing the study on Pupuh Kasmaran. It will also discussed about the \\
& relevance of the value of religiosity with human life in a disruptive era. Data \\
& collection techniques through the study of documents. Data were analyzed by \\
& descriptive-analysis method. From the results of the study note that: there are \\
& four values of religiosity: (1) faith in God, (2) man's obedience to the nature of \\
& God, (3) human obedience to God and (4) human submission to God, and three \\
& dimensions of religiosity: the practical dimension, the ideological dimension, \\
& the knowledge dimension, and the feeling dimension. (2) the value of \\
religiosity in Pupuh Kasmaran is very relevant in human life in the disruptive & era.
\end{tabular}

(C) 2020, Martina Puspita Rakhmi This is an open access article under CC-BY license (c) (i) (D)

How to Cite: Rakhmi, M. P. (2020). Nilai Religiositas Pupuh Kasmaran dalam Lontar Yusuf dan
Relevansinya dengan Kehidupan di Era Disruptif. JURNAL SATWIKA, 4 (1), 56-70.
doi: https://doi/org/10.22219/SATWIKA.Vol4.No1.56-70




\section{Pendahuluan}

Sastra daerah diciptakan tidak hanya sebagai sarana ungkapan hati pengarang ataupun alat manifestasi nilai luhur adat kebiasaan nenek moyang terdahulu. Lebih dari itu, sastra daerah digunakan juga sebagai alat pendidikan dan penyebarluasan agama, salah satunya yaitu Islam. Fenomena Islam di Jawa menurut Endraswara (2018:70) tidak murni seperti bangsa Arab menjalankan ibadah. Kehadiran Islam di Jawa umumnya dipelopori oleh paham mistik kejawen. Paham ini dimotori oleh hadirnya aliran kebatinan di Jawa. Pada saat itu banyak asumsi yang muncul seiring masuknya agama Islam di Jawa. Berbagai tradisi yang biasa dilakukan oleh orang Jawa dianggap syirik. Jika demikian ajaran Islam akan ditolak kehadirannya oleh masyarakat. Untuk itu, para wali memanfaatkan seni tradisi yang populer di Jawa sebagai upaya penyebaran Islam, salah satunya melalui tembang.

Dalam tembang yang disampaikan terkandung ajaran-ajaran tasawuf. Menurut Komarudin (2017), dengan adanya tasawuf, Islam yang diajarkan mempunyai persamaan dengan alam pikiran yang sebelumnya (yang bercorak Hindu) sehingga mudah diterima.

Menurut Poedjasoebroto (dalam Endraswara, 2018:98), tembang berasal dari pengertian karangan bunga (tetambungan kang rinonce kadya kembang), maka tembang juga disebut "sekar" yang merupakan "tembung-kromo dari kembang". Tembang berasal dari jarwo-dhosok: tem + bang, artinya kata yang disusun seperti rangkaian bunga. Dengan demikian, tembang mengandung pengertian keindahan.

Bunga pada umumnya berbau harum. Melalui tembang-tembang tersebut, para wali menyarankan agar dakwah Islam dilakukan seperti menaburkan bunga yang harum, yang menyenangkan, menggembirakan, dan enak didengar, jauh dari dakwah secara polos. Lebih jauh lagi, dakwah yang kasar, disertai memaki-maki, sekalipun benar; menyindirnyindir sampai melukai hati orang perlu dihindari. Ini merupakan dakwah yang jauh dari rasa untuk mendidik rasa segar; gembira dengan tertawa lebih menyenangkan daripada suasana seram, rasa kasih sayang antara manusia perlu ditimbulkan secara positif (Endraswara, 2018:99).

Paham tersebut digunakan oleh para penyebar agama Islam pada tahun 1768 , saat Blambangan runtuh dan Islam menemukan titik terang penyebaran ajarannya (Margana dalam Indiarti, 2018:2). Selain mengenalkan konsep religi, kedatangan Islam juga mengenalkan produk budayanya. Salah satunya adalah tulisan Arab yang beradaptasi menjadi pegon.

Lontar Yusuf Banyuwangi (selanjutnya disingkat LYB) adalah manuskrip kuno yang berisi kisah perjalanan hidup Nabi Yusuf yang ditulis dalam bentuk tembang. LYB memiliki ciri khas, baik unsur tekstual (pengisahan, kosakata, dan bentuk aksara pegon) maupun penyajian yang dihadirkan dalam sebuah ritual dengan iringan musik, dikenal dengan istilah mocoan (Indiarti, 2018:4).

Meskpiun masyarakat Banyuwangi sebagian besar beragama Islam, tetapi mereka juga mempercayai hal-hal mistis dan tidak dapat meninggalkan tradisi leluhur (Maslikatin, 2012). Oleh karena itu, LYB diselenggarakan di beragam ritus slametan (pernikahan, khitanan, atau nadar seseorang). Hal ini merupakan wujud pemahaman pentingnya rasa syukur terhadap siklus kehidupan sekaligus kesadaran masyarakat Banyuwangi dalam menjaga tradisi di tengah budaya dan ajaran baru yang datang menghimpit.

Arus perubahan zaman tidak hanya sekadar proses sharing of information, tetapi juga menyebabkan perubahan identitas budaya yang kemudian menjadi ancaman terhadap keberadaan tradisi lokal, warisan adat leluhur, dan nilai-nilai lokalitas etnik (Madjid dalam Pora, 2014:113), termasuk ancaman untuk LYB.Aksesbilitas teknologi informasi yang sangat mudah dan cepat menimbulkan kemungkinan pemanfaatan yang menyimpang. Menurut Fukuyama (dalam Ohoitimur, 2018:146), di negara manapun kondisi sosial akan memburuk. 
Kejahatan dan kekacauan sosial menciptakan ketidak-nyamanan hidup. Kekerabatan dan keluarga sebagai institusi sosial terguncang, sementara jumlah perceraian meningkat, kualitas pendidikan menurun, kelahiran unwanted-children bertambah, dan hilangnya rasa saling percaya (trust) dalam kehidupan sosial. Dampak-dampak tersebut adalah indikator bahwa telah muncul dua gangguan serius, yaitu melemahnya ikatan sosial dan pudarnya nilai-nilai bersama (common values) yang menjadi modal sosial. Hubungan dua faktor tersebut oleh Ohoitimur (2018:146), disebut sebagai gangguan besar (great disruption) yang berpotensi memerosotkan peradaban. Ditambah lagi, menurut Murniati (dalam Sholekhah, 2019:70), realita permasalahan bangsa Indonesia sekarang yakni merosotnya nilai etika, kurangnya kesadaran terhadap nilai-nilai budaya, dan melemahnya kemandirian bangsa. Untuk menangani dampak-dampak tersebut perhatian perlu diarahkan kepada dua kapasitas manusiawi, yaitu kesadaran akan kodrat manusia dan kecenderungan manusia untuk mengorganisasi diri.

Kaitannya dengan hal ini, LYB sebenarnya dapat dijadikan sebagai salah satu alat pengajaran untuk menyadarkan kodrat manusia sekaligus mengorganisasi dirinya. Namun kendala terjadi karena LYB dianggap sebagai selera tua. Kenyataan ini mengindikasikan bahwa modernitas telah mengikis tradisi sementara dalam tradisi itulah terdapat pegangan hidup untuk menghadapi segala tuntutan perubahan zaman.

Kenyataan lain ada pada kisah pemudapemudi Banyuwangi yang tergabung dalam "Komunitas Mocoan Milenial" dengan visi mengglobalkan LYB agar tetap hidup, jumlahnya masih sangat sedikit. Menurut hasil wawancara dengan Naufal Anfal (Ketua Komunitas Mocoan Milenial), hal yang paling miris adalah anggota komunitas hampir $80 \%$ berasal dari daerah Banyuwangi bagian selatan (Muncar, Songgon, dan Kalibaru). Sementara pemuda-pemudi pemilik cenderung tidak peduli. Padahal kelestarian sebuah tradisi bergantung pada masyarakat pemilik.

Penelitian terdahulu terkait LYB pernah dilakukan pada tahun 2016 oleh Rofiq, Degeng, Hidayah, and Atmoko (2016). Penelitian tersebut menawarkan konsep, bahwa dalam LYB terdapat nilai budaya yang lebih cocok dengan karakter dan budaya masyarakat Indonesia dibanding bahan konseling ala Barat. Nilai-nilai budaya LYB dianggap dapat digunakan sebagai acuan praktik konseling di sekolah-sekolah Banyuwangi. Dalam penelitian tersebut, seluruh pupuh pada LYB diulas namun ulasan tidak merata dan spesifik. Adapun pengaitan pada praktik konseling juga tidak dipaparkan secara teknis.

Penelitian lain dilakukan oleh Estriana (2017). Estriana mengkaji LYB dari segi sejarah manuskrip yang digunakan sebagai media dakwah. Pada tahun (2018), Indiarti melakukan penelitian terhadap LYB dengan mentranliterasi dan menerjemahkan LYB secara keseluruhan. Data yang digunakan berupa salinan manuskrip terakhir dan sifatnya identik. Dalam penelitiannya itu, Indiarti juga memapararkan identitas LYB secara penuh, mulai dari sejarah naskah, bentuk naskah, hingga penyajian naskah. Namun dalam penelitiannya tersebut, tidak ada penginterpretasian pupuh atau pengkajian nilai-nilai budaya dalam pupuh.

Bertolak dari fakta-fakta mengenai keterancaman LYB di tengah arus era disruptif, maka perlu diadakan penelitian yang sangat mendesak untuk menemukan dan meneguhkan kembali ruh LYB. Maka dalam penelitian ini dikaji secara khusus nilai-nilai budaya, berupa nilai religiositas pada Pupuh Kasmaran I, III, dan XII (yang selanjutnya disingkat PK). Nilai religiositas dipilih karena nilai ini adalah yang paling dominan dalam LYB. Fokus kajian dalam penelitian ini menjadi pembeda sekaligus pelengkap dari kajian penelitian-penelitian sebelumnya.

Rumusan masalah yang diajukan ada dua. Pertama mengenai nilai-nilai religiositas pada PK. Kedua, keterkaitan nilai-nilai religiositas PK dengan kehidupan 
di era disruptif. Diharapkan dengan adanya penelitian ini, nilai-nilai religiositas LYB khususnya pada PK dapat dikenali sehingga ajaran-ajaran agama Islam di dalamnya dapat digunakan sebagai pegangan dalam mengontrol diri yang pada akhirnya berimbas pada pengontrol tatanan nilai-nilai sosial.

LYB adalah puisi naratif yang menceritakan kehidupan Nabi Yusuf sejak usia dua belas tahun. Saat bermimpi tentang matahari, bulan, dan sebelas bintang bersujud padanya sampai ia naik tahta menjadi raja, seusai nubuatnya tentang mimpi Raja Mesir; tujuh sapi kurus memangsa tujuh sapi gemuk dan tujuh daun kering melahap tujuh daun hijau (Indiarti, 2018:1).

LYB terdiri dari 12 pupuh, 593 bait dan 4.366 larik. Jenis pupuh dalam LYB ada empat, yaitu Kasmaran, Durma, Sinom, dan Pangkur. Berikut rinciannya: I Kasmaran (109 bait; 763 larik), II Durma (2 bait; 16 larik), III Kasmaran (65 bait; 455 larik), IV Pangkur (51 bait; 357 larik), V Sinom (5 bait; 45 larik), VI Pangkur (28 bait; 196 larik), VII Durma (7 bait; 616 larik), VIII Pangkur (46 bait; 322 larik), IX Sinom (8 bait; 72 larik), $\mathbf{X}$ Pangkur (96 bait; 672 larik), XI Sinom (55 bait; 495 larik), XII Kasmaran (51 bait; 357 larik).

Bahasa yang digunakan dalam LYB sebagian besar adalah bahasa Jawa, (Jawa Baru \& Jawa Kuno (Kawi)). Dalam beberapa bagian, istilah bahasa Using dan bahasa Arab juga digunakan. LYB sebagai tradisi lisan sebab dalam penyajiannya dilakukan secara lisan. LYB sebagai tradisi tulis sebab sejak ditulis pertama kali hingga kini, dilakukan penyalinan secara terus menerus. Penyalinan dilakukan untuk memenuhi hasrat bila seseorang atau kelompok hendak mempelajari LYB.

$P K$ berada pada pupuh pertama, ketiga dan keduabelas. Berikut ringkasan cerita sebagai gambaran isi pupuh.

Pupuh I: Kasmaran $\left(\mathrm{P}^{1} \mathrm{~K}\right)$ diawali dengan doa pembuka berisi harapan keselamatan. Lalu berlanjut pada kisah Nabi Yusuf yang mendapat mimpi berupa matahari, bulan, dan bintang yang bersujud padanya. Nabi Yakub menafsirkan bahwa matahari adalah Yakub, bulan adalah ibunya, dan sebelas bintang adalah kesebelas saudara laki-laki Yusuf. Semua tunduk karena kelak Nabi Yusuf akan menjadi raja. Hal itu membuat ibu tiri Yusuf dan kesebelas saudara laki-lakinya iri dan memiliki niat jahat.

Keesokan harinya, sebelas saudara Yusuf mengajak berburu ke hutan. Di sana Yusuf hendak dibunuh tapi urung karena banyak keraguan. Akhirnya Yusuf dimasukkan ke dalam Telaga Syadat. Kesebelas saudara Yusuf pun melakukan kebohongan pada Yakub. Mereka berkata jika Yusuf telah dimakan harimau. Di luar dugaan, harimau justru bercerita kepada Yakub bila ia tidak melakukan apapun. Harimau justru sedang bersedih karena kehilangan anaknya. Sama seperti Yakub yang kehilangan Yusuf.

Pupuh III: Kasmaran $\left(\mathrm{P}^{\mathrm{III}} \mathrm{K}\right)$ menceritakan pertemuan Malik dengan Yusuf di dalam telaga. Ketika pertemuan itu berlangsung, saudara-saudara Yusuf datang. Mereka mengaku bahwa Yusuf adalah budak mereka. Yusuf budak yang buruk peringainya. Mereka hendak menjual Yusuf. Malik pun membeli Yusuf. Yusuf hanya dapat menatap sedih pada kesebelas saudaranya. Melihat Yusuf seperti itu, terbukalah mata hati mereka dan timbul perasaan menyesal.

Yusuf sebagai budak Malik mengikuti ke mana pun rombongannya pergi. Di tengah perjalanan, rombongan melewati pusara makam ibunda Yusuf. Di sanalah Yusuf mengadukan nasibnya hingga tidak sadarkan diri karena dilanda kesedihan yang begitu mendalam. Kesalahpahaman terjadi. Ketika Yusuf pingsan dan tidak terlihat di tempatnya, rombongan mengira Yusuf melarikan diri. Setelah menemukan keberadaan Yusuf, ia diseret, dipukuli, dan dirantai agar tidak dapat melarikan diri.

Pupuh XII: Kasmaran $\left(\mathrm{P}^{\mathrm{XII}} \mathrm{K}\right)$ menceritakan kisah Yusuf setelah dipenjara selama lima tahun. Yusuf dibebaskan sebab mampu menafsirkan mimpi Raja. Mimpi tentang tujuh ekor sapi gemuk dimakan tujuh sapi kurus dan tujuh lembar daun hijau 
dilahap tujuh daun kering. Yusuf menyampaikan makna mimpi kepada raja tentang musibah yang akan menimpa Mesir.

Raja diminta untuk membuat lahan pertanian, lumbung, dan êmbung. Sebagai rasa terima kasih dan balas budi, raja menyerahkan semua yang dimilikinya kepada Yusuf. Raja memutuskan untuk menjadi pertapa dan Yusuf menjadi Raja Mesir.

Berbagai gambaran tersebut memperlihatkan nilai religius yang ada di dalam teks. Nilai religius atau religiositas merupakan konsep mengenai penghargaan tinggi yang diberikan oleh warga masyarakat kepada beberapa masalah pokok dalam kehidupan keagamaan yang bersifat suci sehingga dijadikan pedoman bagi tingkah laku keagamaan warga masyarakat yang bersangkutan. Makna religiositas lebih luas (universal) daripada agama, karena agama terbatas pada ajaran-ajaran atau aturan-aturan, berarti mengacu pada agama (ajaran) tertentu (Tresna, Maryana, Fatimah, \& Priyanto, 2018:209).

Chatters (dalam Bakry, 2016:187) memaknai religiositas sebagai sikap keberagamaan yang berarti adanya unsur internalisasi agama ke dalam diri seseorang. Selain itu, pendapat lain mengatakan bahwa religiositas merupakan sebuah proses untuk mencari sebuah jalan kebenaran yang berhubungan dengan sesuatu yang sakral. Karena religiositas menurut Adisubroto (dalam Bakry, 2016:191) adalah sebuah ekspresi spiritual seseorang yang berkaitan dengan sistem keyakinan, nilai, hukum yang berlaku dan ritual. Maka religiositas menjadi aspek yang dihayati oleh individu di dalam hati, getaran hati nurani pribadi, dan sikap personal.

Mengutip pandangan Glock dan Stark (dalam Bakry, 2016:191), ada lima dimensi religiositas, yaitu 1) Religious Practice (The Ritualistic Dimension). Tingkatan seseorang mengerjakan kewajiban ritual di dalam agamanya, seperti shalat, zakat, puasa dan sebagainya. 2) Religious Belief (The Ideological Dimension). Sejauh mana seseorang menerima hal dogmatik di dalam ajaran agamanya. Misalnya kepercayaan tentang adanya Tuhan, malaikat, kitab, nabi dan rasul, hari kiamat, surga, neraka dan yang lain-lain yang bersifat dogmatik. 3) Religious Knowledge (The Intellectual Dimension). Seberapa jauh seseorang mengetahui tentang ajaran agamanya. Hal ini berhubungan dengan aktivitas seseorang untuk mengetahui ajaran-ajaran dalam agamanya. 4) Religious Feeling (The Experiental Dimension). Dimensi yang terdiri dari perasaan dan pengalaman keagamaan yang pernah dirasakan dan dialami. Misalnya merasa dekat dengan Tuhan, merasa takut berbuat dosa, merasa doanya dikabulkan Tuhan, dan sebagainya. 5) Religious Effect (The Consequential Dimension). Dimensi yang mengukur sejauh mana perilaku seseorang dimotivasikan oleh ajaran agamanya di dalam kehidupannya. Misalnya ikut dalam kegiatan konservasi lingkungan, ikut melestarikan lingkungan alam dan lain-lain.

Menurut Djamaris (dalam Subadiyono, 1999:5), perwujudan hubungan manusia dengan Tuhan adalah nilai ketaqwaan, suka berdoa, dan berserah diri kepada kekuasaan Tuhan. Di dalam hubungan manusia dengan Tuhan, terdapat kewajiban manusia terhadap Tuhan, yaitu 1) keimanan terhadap Tuhan, 2) keteringatan manusia terhadap sifat Tuhan, 3) ketaatan manusia terhadap Tuhan, dan 4) kepasrahan manusia terhadap Tuhan.

Fukuyama (dalam Ohoitimur, 2018:145) mengartikan disrupsi sebagai "gangguan atau kekacauan". Menurutnya, suatu masyarakat yang dikondisikan oleh kekuatan informasi cenderung menghargai nilai-nilai yang dijunjung tinggi dalam demokrasi, yaitu kebebasan (freedom) dan kesetaraan (equality). Namun tercipta pula kejahatan, kekacauan dan pergeseran tatanan sosial.

Selama ilmu pengetahuan dan teknologi masih terus berkembang, disrupsi akan terjadi. Menurut Fukuyama, agar kita bisa menata kembali masyarakat secara sosial, perhatian perlu diarahkan kepada dua kapasitas manusiawi, yaitu kesadaran akan kodrat manusia dan kecenderungan manusia untuk mengorganisasi diri. Faktor pertama menjadi sumber nilai-nilai sedangkan yang 
kedua merupakan wilayah operasional bagi modal sosial.

Tatanan sosial sering disebut sebagai tatanan masyarakat yang artinya adalah keseluruhan dari ikatan peraturan dan kelembagaan yang secara khusus mengatur struktur masyarakat, hubungan antar-anggota masyarakat hingga hubungan antarkelompok masyarakat. Norma-norma dalam tatanan masyarakat mengatur segala bentuk status masyarakat yang terikat di dalamnya (Turahmat, 2019:90). Menurut Berger (dalam Sulaiman, 2016:19) tatanan sosial terbentuk secara terus-menerus yang bermula dari eksternalisasi, yakni pencurahan kedirian manusia secara terus menerus ke dalam dunia, baik dalam aktivitas fisik maupun mentalnya.

\section{Metode}

Data yang digunakan dalam penelitian ini adalah $\mathrm{PK}\left(\mathrm{P}^{1} \mathrm{~K}, \mathrm{P}^{3} \mathrm{~K}, \& \mathrm{P}^{12} \mathrm{~K}\right)$. Instrumen utama dalam penelitian ini adalah peneliti sendiri. Pengumpulan data dilakukan melalui teknik dokumentasi. Sumber data yang digunakan adalah LYB (Indiarti, 2018). Sumber data tersebut dipilih karena naskah LYB yang dicantumkan adalah hasil scanning dari naskah salinan asli Carik Pak Jannah (penyalin naskah LYB), sifatnya identik. Seperti dikatakan Baried (dalam Harsena \& Holil, 2018:694) edisi naskah tunggal digunakan apabila hanya ada naskah tunggal dari suatu tradisi sehingga perbandingan tidak mungkin dilakukan dan dapat dianggap sebagai codex unicus, naskah satu-satunya.

Dalam analisis data, metode yang digunakan yaitu deskriptif-analisis konten (content analysis). Keduanya dilakukan bersamaan. Analisis deskriptif merupakan teknik analisis data yang mendeskripsikan data apa adanya sehingga dapat menimbulkan kejelasan dan kemudahan bagi pembaca. Analisis isi berusaha menganalisis dokumen agar diketahui isi dan makna PK (Supanggih, Ferdyani, \& Dwi, 2017:24).

Teknik wawancara juga dilakukan untuk menggali pengetahuan nilai religiositas yang dipahami kelompok pelestari LYB. Namun, hasil wawancara tersebut hanya dijadikan sebagai pendukung hasil analisis.

\section{Hasil dan Pembahasan \\ 3.1 Nilai Religiositas}

Setelah melakukan analisis data, penelitian menunjukkan bahwa terdapat empat kelompok nilai religiositas dalam Pupuh Kasmaran (I, III, dan XII), yaitu 1) keimanan terhadap Tuhan, 2) keteringatan manusia terhadap sifat Tuhan, 3) ketaaatan manusia terhadap Tuhan, dan 4) kepasrahan terhadap Tuhan. Berikut pemaparannya.

\section{1) Keimanan terhadap Tuhan}

Termuat dalam P $\mathrm{P}^{\mathrm{I}} \mathrm{K}$ bait ke-93-94.

\section{Mêngkana malih ing binjing / ing ari kiyamat ika / anglakoni kang tan sarèh / ma siyat linging tingkah / pinariksa ing ngastana / tananganggo pulah epun / lamun akarya ma'siyat // Irika asta nirangling / angaku lamun duraka / pada nira matur age / lamun sira ma'siyat / sagunge panggahota / sêdaya sami angaku / kawêlèh ingawak dhawak //}

Demikianlah kelak / pada saat hari kiamat / yang berlaku tiada sabar / berbuat penuh maksiat / diperiksa di alam kubur / tiada bisa mengelak / jika telah berlaku maksiat // Kedua tangannya berkata / mengaku jika digunakan berbuat cela / kedua kakinya pun berkata / jika digunakan berbuat maksiat / segenap anggota badannya / semua akan bersaksi / maka dirinya laksana terhempas //

Kedua bait tersebut menyampaikan perihal yang akan terjadi di dunia akhir, semua makhluk akan mengalami yaumul hisab. Semua hal yang baik dan buruk dipertimbangkan. Semua anggota tubuh bersaksi. Pada saat itu, semua manusia tidak bisa mengelak atas apa yang pernah dilakukan.

Percaya akan hari akhir atau hari kiamat berarti percaya dan beriman kepada Tuhan. Seperti yang disampaikan oleh Thoyyibah (2016:18) seseorang yang mempunyai iman 
biasanya memiliki perilaku baik dan meneladani amal saleh. Tidak hanya iman kepada Allah namun juga iman kepada kitab-kitab, iman kepada rasul dan hari kiamat, serta iman kepada qodha dan qodar.

Keimanan tidak dapat hanya terbatas pada pengakuan dari hati, tetapi perlu diucapkan secara lisan dan diwujudkan melalui perilaku sehari-hari. Dengan demikian barulah seseorang benar-benar dapat dikatakan telah beriman kepada Tuhan. Keimanan yang dimiliki seseorang akan menjadi penuntun dan pengingat (pengontrol) tingkah laku di dunia sebab orang tersebut tahu dan yakin bahwa segala yang ada di dunia akan dipertanggungjawabkan. Maka, dalam hidupnya akan selalu berhati-hati.

Nilai religiositas selanjutnya termuat dalam bait ke-90. Disampaikan bila seseorang yang percaya akan kasih Tuhan maka ia akan mendapat ampunan dari Tuhan. Manusia yang benar tauhidnya maka akan hilang segala duka lara di hatinya.

Isi bait tersebut selaras dengan firman Allah, yakni "Allah sesuai prasangka hamba-Nya". Bila manusia menyangka Allah tidak adil, maka dalam hidupnya ia akan merasa paling menderita dan sengsara. Ia akan merasa hal-hal buruk akan selalu menimpa hidupnya.

Berkebalikan dengan seorang manusia yang merasa Allah Mahabaik dan penyayang. Dalam hidupnya, ia akan senantiasa merasa dicintai Allah. Meski kemalangan merundunginya, orang tersebut akan merasa bahwa Allah sedang menyiapkan hadiah untuknya melalui ujianujian hidup.

Selalu berprasangka baik kepada Tuhan menjadikan seseorang sabar. Menurut Harsena and Holil (2018:700) sabar berarti dapat mengendalikan segala tingkah laku yang diperbuat. Kesabaran menjadi wujud cinta manusia kepada Tuhan. Ketika cinta kepada Tuhan hadir dalam diri seseorang, maka ia akan terpelihara, terjaga, menghindarkan diri dari larangan-larangan Tuhan, senantiasa teguh pada ketauhidannya, dan mendapat ampunan dari Tuhan hingga hilang segala rasa sedih di hatinya.

Pada $\mathrm{P}^{\mathrm{III}} \mathrm{K}$ bait ke-14, terdapat syair seperti di bawah ini.

\section{Wontên wahyune Yang Widi / maring Nabi Dawud ika / sing sapa apaksa kabèh / angulatana ing ring wang / pasti ningsun kapêndhag / lawan malih wong dèn têmu / sun wèhi waspadeng tingal //}

Ada wahyu dari Tuhan / kepada Nabi Daud / siapa yang bersungguh-sungguh / mencari diri-Ku / tentu akan menemukan / dan apabila telah bertemu / Kuberikan penglihatan yang tajam //

Bait tersebut berisi janji Allah kepada Nabi Daud. Janji ini pula yang diberikan kepada seluruh umat-Nya. "Barang siapa yang berjalan ke arahku, maka aku akan berlari ke arahnya." Firman Allah yang demikian, dapat dimaknai bahwa tidak ada yang perlu dicari manusia dalam hidupnya di dunia. Manusia hanya perlu mencari-Nya dengan sungguh-sungguh.

Kesungguhan yang dilakukan manusia untuk mencari ke-Esa-an Allah juga memiliki arti bahwa manusia telah siap meninggalkan semua hal yang bersifat keduniawian. Kesiapan ini pula yang justru menjadi awal bahwa Allah akan mencukupkan semua yang dibutuhkan manusia di dunia ini.

Selanjutnya pada $\mathrm{P}^{\mathrm{III}} \mathrm{K}$ bait ke-18 sampai 21 diceritakan Malik (sang pedagang) dan para budaknya berangkat mencari Yusuf. Yusuf berada di dalam telaga. Sang pedagang melihat burungburung banyak mengitari telaga seperti orang naik haji yang mengitari Ka'bah. Tingkah burung-burung itu adalah jelmaan malaikat yang sedang menunggui Nabi Yusuf berkat kemuliaan Tuhan. Sang pedagang menyuruh para budak memeriksa ke dalam sumur dan di sana tercium semerbak bau wangi.

Keimanan terhadap Tuhan pada bait tersebut tercermin pada sikap Malik yang percaya bahwa Tuhan akan senantiasa 
memberi petunjuk pada hamba-Nya. Allah pun mengirim pasukan malaikat untuk menunggui Yusuf sekaligus memberi petunjuk pada Malik.

Hal di atas sebagai bukti bahwa sebenarnya sampai kapanpun Tuhan tidak pernah meninggalkan hamba-Nya. Justru manusia yang selalu lalai dan meninggalkan Tuhan sebab terlalu sibuk mencari hal keduniawian. Patutlah seorang hamba yang baik selalu iqra (membaca). Maka ia tidak perlu sibuk mencari-cari yang sebetulnya tidak perlu dicarinya.

Berdasarkan pandangan Glock dan Stark, semua bentuk keimanan terhadap Tuhan pada kategori ini termasuk ke dalam religious belief (the ideological dimension) atau dimensi ideologi. Semua bentuk keimanan dalam kategori ini bersifat dogmatik. Keimanan yang serba dipaksakan untuk diimani. Pemaksaan iman ini yang memunculkan keyakinan atau kepercayaan dalam diri manusia kepada Tuhan. Dan ini menjadi dasar dari semua prasangka manusia terhadap ke-Esa-an Tuhan, sekaligus dasar atau awal mua bentukbentuk nilai religiositas yang lainnya.

\section{2) Keteringatan Manusia terhadap Sifat Tuhan}

$\mathrm{P}^{\mathrm{I}} \mathrm{K}$ bait pertama sampai ke-3. Pada serangkaian bait ini berisi puji-pujian akan kerupawanan, sikap mulia, dan kemuliaan hati Nabi Yusuf. Secara tersurat memang pujian tersebut ditujukan kepada Nabi Yusuf, namun sebenarnya ini adalah pujipujian hanya untuk Allah Swt. Tidak akan ada kemuliaan dalam diri Nabi Yusuf jika bukan dari pemberian Allah. Di sini sepatutnya pula kita semua memuji suatu hal hanya karena kebesaran Allah.

Pada bait ke-52 sampai 54 disampaikan sebuah sabda Tuhan bahwa Tuhan menempatkan segala kemuliaan bercampur dengan yang tiada berharga. Seperti tempatnya mutiara ditempatkan dalam anting-anting. Kasturi dan sutra ditempatkan pada ulat yang indah. Madu tempatnya pada tawon. Logam emas dalam batu. Iman berada dalam dada.
Demikianlah pencarian itu, dalam sesuatu yang tidak bernilai jika dicermati seluruhnya yang bernilai ada di dalam yang tak bernilai.

Selayaknya manusia ingat akan sifat Tuhan ini. Tuhan selalu memberi pelajaran berharga dalam setiap musibah yang menimpa diri manusia. Tuhan selalu memberi kebaikan di setiap keburukan. Bait ini menjadi pengingat bagi kita semua untuk senantiasa membaca pesan-Nya. Berpikir dan melihat dengan jernih apa yang ada di balik semua peristiwa. Hingga dapat menghayati pesan-Nya. Pada tahap ini barulah manusia bisa sadar bahwa dirinya sedang belajar. Pembelajaran ini yang dimaksudkan hal berharga sebab membuat manusia bernilai sebagai insan.

Selanjutnya pada $\mathrm{P}^{\mathrm{III}} \mathrm{K}$ bait ke-65 diceritakan bahwa Yusuf bersumpah semoga ia mendapat murka dari Tuhan jika ia melarikan diri sebab Yusuf hanya pergi ke pusara ibunya. Keinginan Yusuf mendapat murka Tuhan adalah bentuk keteringatannya akan sifat Tuhan yang tidak suka pada hamba yang suka berdusta. Tuhan selalu melihat hal yang dilakukan hamba-Nya, selalu mengetahui isi hati hamba-Nya. Meski semua ditutupi sampai dasar lubuk hati sekalipun. Bila hanya perbuatan tercela dan manusia tidak mau mengakui, Tuhan benar-benar tidak menyukainya dan pasti akan menimpakan ganjaran yang sesuai. Oleh karena itu, dalam bait tersebut, Yusuf berani menerima murka Tuhan.

Senantiasa mengingat sifat-sifat Tuhan, perasaan selalu dekat dengan Tuhan akan selalu ada. Begitu pula sebaliknya, dengan selalu merasa bahwa Tuhan itu dekat dengan kita, maka akan senantiasa teringat sifat-sifat Tuhan. Keteringatan sifat Tuhan selalu mengaitkan sifat dan perasaan manusia, maka jelas kategori ini termasuk ke dalam dimensi perasaan (perasaan dekat dengan Tuhan) religious feeling (the experiental Dimension).

\section{3) Ketaatan Manusia terhadap Tuhan}

Dalam hal ini, ketaatan manusia terhadap Tuhan, terwujud dalam beberapa 
sikap berikut. Ketaatan untuk selalu jujur termuat dalam $\mathrm{P}^{\mathrm{I}} \mathrm{K}$ bait ke-34.

\section{Anglujiteng jêroning ati / Bagendha Yusup kewuhan / apajaring sêwapnane / dadêya wong murtading rama / yèn ingsung tana warta / kêna linyok awak ingsung / ingsung tan arsa linyoka //}

Dirasakan di dalam hatinya / Baginda Yusuf susah hatinya / kalau impiannya dikatakan / ia mendurhakai ayahnya / kalau aku tak menceritakannya / maka aku berdusta / aku tidak ingin berdusta //

Dalam keadaan sempit, saat didesak kesebelas saudaranya, Yusuf benar-benar tidak bisa berbohong. Seperti dua mata pisau, jika jujur, dia ingat akan larangan Ayahnya. Ini berhubungan dengan kepatuhan seorang anak kepada orang tuanya. Bila tidak mengatakan yang sebenarnya, sama halnya berdusta.

Ajaran jujur juga tertuang pada bait ke99 sampai 101. Diceritakan bahwa macan takut mengatakan yang sesungguhnya. Ia takut dituduh telah membuat fitnah. Macan tidak membunuh Yusuf. Kesebelas saudara Yusuf lah yang berusaha mencelakai Yusuf. Sementara di bait ke-105 sampai 108 diceritakan bahwa macan takut menceritakan yang sebenarnya karena ia takut jika disangka mengadu domba Yakub dengan anak-anaknya. Macan tahu, jika ia berbohong, maka Tuhan tidak akan menempatkannya di surga.

Manusia yang jujur memiliki keimanan bahwa Tuhan selalu melihat semua yang dilakukan hamba-Nya. Ketika ia tidak menyampaikan yang sebenarnya, ada rasa tidak nyaman dalam hatinya. Ini menandakan bahwa keimanan sudah termaktub dalam hatinya sehingga memunculkan ketaatan dalam bentuk sikap jujur.

Wujud ketaatan yang lain adalah sikap yang selalu bersyukur, termuat dalam $\mathrm{P}^{\mathrm{I}} \mathrm{K}$ bait ke-29.
Lingira nabYa'kub malih / ayuwa tan wêruh sira / tuwan sih panggunggung Yang Manon / sukura kêna dênira / asih mulyaning pangeran / èstu suwapna nireku / mapan nabi sira tuwan //

Nabi Yakub lalu berkata lagi / jangan tiada kau ketahui / Engkau diliputi kasih Tuhan / penuh syukurlah dirimu / atas kasih kemuliaan dari Tuhan / sungguh impianmu itu / dinobatkan engkau sebagai Nabi //

Bait ini berisi nasihat Yakub kepada Yusuf agar mensyukuri pemberian Tuhan. Dalam pupuh, segala nasihat atau ajaran ditujukan kepada pendengar. Maka, nasihat ini bukan sebatas cerita namun lebih tepat ditujukan kepada semua manusia. Dengan pemberian Tuhan yang lain, seperti kesehatan, rezeki, rasa tenang, dan damai.

Ajaran untuk bersyukur juga termuat dalam $\mathrm{P}^{\mathrm{III}} \mathrm{K}$ bait ke-7.

Lawan sira suka sugih / dening rare alit ika / tumêkeng lèrira têmbe / tan pêgat sira ing ngucap / têkeng ari qiyamat / saking bêrkating rareku / luput ing api nêraka //

Kau akan dilimpahi kekayaan / atas perantara anak kecil itu / sampai saatnya tiba kelak / janganlah putus berucap (syukur) / hingga hari kiamat / dikarenakan atas berkat anak kecil itu / diluputkanlah dari api neraka //

Pencarian Malik terhadap Yusuf dilatarbelakangi oleh mimpi yang didapat Malik kala itu. Malik bertanya kepada pendeta tentang mimpinya. Pendeta tidak henti-hentinya menyampaikan agar Malik terus bersyukur. Malik mendapat banyak berkat.

Dalam konteks kehidupan duniawi, banyak orang mengingkari ajaran ini sebab sifatnya yang terlalu dogmatik. Agar dapat menerimanya secara akal, maka persepsi secara logis perlu digunakan. 
Bersyukur berarti menerima dengan lapang hati. Ketika seseorang sudah mampu bersyukur berarti dia mampu untuk tidak berharap lebih apalagi membandingbandingkan dengan kehidupan orang lain. Seseorang yang sudah bersyukur, berarti sadar jika sikap berharap lebih dan membandingkan hanya akan menghabiskan waktu dan energi untuk hal yang belum tentu menjadi miliknya. Kesadaran itu yang membuat hidup seseorang tidak diliputi rasa cemas. Hanya kedamaian yang dia rasakan. Bersyukur menjadi keharusan sebab seperti yang disampaikan Harsena and Holil (2018:701), ketika manusia mendapat kemuliaan berarti manusia tersebut dikasihi oleh Allah, yang senantiasa mengingat-Nya.

Ajaran berbuat baik tertuang pada $\mathrm{P}^{\mathrm{I}} \mathrm{K}$ bait ke-36.

\section{Ênêngêna wangseki / sabda rasul kang kocapa / ing wong sadêya ngêrusak mangko / lampah ingkang tan yuktêya / tan pindah bahning punang / anggêsêngi ing rêbeku / mêngkana manah niyaya //}

Tinggalkanlah sejenak sanak kerabat itu / Sang Rasul bersabda / manusia yang berbuat kerusakan / bertingkah tiada sepantasnya / tiada beda layaknya api / yang membakar rusak / menjadikan hati teraniaya //

Bait di atas berisi sabda Rasul tentang manusia yang berbuat tercela diumpamakan sebagai api yang merusak sekitarnya. Perumpamaan ini dibuat dengan tujuan agar pembaca lebih dapat menerima maksud isi pesan, berbuat baik untuk sesama, memberikan manfaat sebanyak-banyaknya, seluas-luasnya. Sekecil apapun perbuatan yang dilakukan manusia, yang dilakukan dari hati, akan menjadi manfaat untuk sekitarnya. Sikap manusia yang tercela hanya ada ketika tidak ada terang dalam hatinya. Jauh dari cahaya, kasih, dan ajaran Tuhan. Dalam hidupnya juga jauh dari rasa tenang dan damai.
Bentuk ketaatan manusia kepada Tuhan adalah beribadah, dimuat dalam $\mathrm{P}^{\mathrm{I}} \mathrm{K}$ bait ke53.

\section{Anêngakêna rumehin /wong Bani Syerail kocapa / atapa lintang baktine / rolas tahun laminira / muji ngaji puwasa / dadi kapingin ing wahu / wikana ingbêlis la'nat //}

(Tinggalkanlah sejenak / diceritakanlah tentang seorang Bani Israil / sedang bakti bertapa / dua belas tahun lamanya / memuja, mengaji, dan berpuasa / karena ia memiliki kehendak / untuk mengetahui iblis laknat.)

Dalam pertemuannya, iblis mengatakan jika pertapa masih memiliki sisa usia di dunia selama 200 tahun karena merasa masih lama, pertapa keluar dan berbuat maksiat demi melampiaskan hawa nafsu yang selama ini tertahan. Setelah itu, tanpa bertobat, pertapa mati.

Terdapat pula perihal bertapa dalam $\mathrm{P}^{\mathrm{I}} \mathrm{K}$ bait ke-68 sampai 70. Bertapa karena sang pertapa memiliki keinginan untuk bertemu dengan Yusuf sebelum pertapa itu mati. Tuhan mengabulkan keinginan pertapa. Pertapa bertemu dengan Yusuf dalam telaga. Setelah bertemu, pertapa itu meninggal.

Di ${ }^{\mathrm{XII}} \mathrm{K}$ bait ke-50 diceritakan bahwa Raja Mesir menyerahkan semua kekuasaannya pada Yusuf karena sang raja hendak bertapa. Keputusan untuk bertapa secara tersurat untuk membalas budi pada Yusuf. Namun secara tersirat, dilakukan untuk melepas semua keduniawian yang selama ini ditanggungnya sekaligus mendekatkan diri pada Tuhan. Mendekatkan diri dalam keadaan tidak membawa apa-apa. Hanya Tuhan yang dituju. Maka diceritakan di akhir bait jika tidak ada seorang pun yang tahu kapan raja pergi dan bagaimana nasibnya kemudian.

Takdir Tuhan akan meliputi segala hal, termasuk di dalamnya semua yang ada pada diri seseorang. Takdir tidak bisa diubah, manusia hanya dapat mendasarkan diri pada kehendak (takdir), berikhtiar, dan disertai 
dengan watak eling (sadar). Hidup tak harus bersenang-senang. Hanya saja, hidup memang harus dijalani dengan perasaan senang. Dengan mengetahui asal-usul kejadiannya, manusia akan semakin insyaf bahwa hidup harus dijalani dengan ibadah (Endraswara, 2018:111). Dasar ini yang kemudian menjadi alasan bahwa tidak ada hal lain selain mejalani kodrat hidup manusia sebagai hamba Tuhan untuk selalu beribadah.

Ajaran untuk tidak memuji diri sendiri terdapat pada $\mathrm{P}^{\mathrm{III}} \mathrm{K}$ bait ke-25 sampai 28 , diceritakan dialog antara Yusuf dan Jibril saat di dalam telaga. Yusuf bercermin sambil tersenyum-senyum. Yusuf merasa bila dirinya terlalu rupawan hingga tidak ada harga yang layak jika ada yang ingin membelinya. Mendengar itu, Jibril memperingatkan Yusuf jika pujian hanya untuk Tuhan. Itulah semurni-murninya pujian. Pujian kepada hal lain termasuk untuk dirinya sendiri hanya akan menjauhkan diri pada Tuhan. Itulah sikap sombong manusia. Bila Tuhan melihat seseorang, tidak pernah Tuan melihat bagaimana rupanya, bagaimana pekerjaannya. Tuhan hanya melihat kemuliaan hatinya.

Pada $\mathrm{P}^{\mathrm{I}} \mathrm{K}$ bait ke-52, berisi peringatan untuk umat manusia agar segera bertobat. Bermohon kepada Tuhan akan pengampunan-Nya atas laku yang tidak pantas, atas dosa besar yang berasal dari bisik rayuan setan. Tindakan yang patut dilakukan manusia sebagai seorang hamba mengakui semua kesalahannya dan mengakui keadaan dirinya serendahrendahnya di hadapan Tuhan. Bertobat berarti mengakui dan menerima bahwa dirinya telah lalai sebagai makhluk yang memiliki ketetapan hidup.

Bentuk ketaatan selanjutnya berupa bertutur kata baik terdapat pada $\mathrm{P}^{\mathrm{III}} \mathrm{K}$ bait ke47 sampai 50. Bait-bait itu menceritakan saat Yusuf dijual kepada saudagar (Malik). Sedih hati Yusuf atas perilaku semua saudarasaudaranya. Yusuf menangis dan menatap semua saudaranya, satu per satu. Yusuf ingin melihat saudara-saudaranya untuk terakhir kalinya. Mendengar ucapan Yusuf, semua saudara menangis. Timbul rasa kasih, sedih, dan sesal dalam hati semua saudara Yusuf.

Tuturan yang baik dan halus lebih mudah diresapi oleh pendengar, akan lebih mudah membuka setiap hati dan jiwa yang keras dan kosong. Itu karenanya Tuhan ingin semua hamba-Nya untuk terus bertutur kata baik. Tuturan yang baik juga bentuk prasangka yang baik kepada Tuhan, bahwa semua yang terjadi atas izin-Nya.

$\mathrm{P}^{\mathrm{XII}} \mathrm{K}$ bait ke-5 sampai 11 berisi cerita tentang raja yang resah akan makna mimpinya. Raja meminta semua ahli kerajaan untuk mengungkap makna mimpi yang dialaminya. Namun tidak ada yang berhasil. Tiba-tiba, penjaga gerbang teringat akan pesan Yusuf. Yusuf meminta penjaga gerbang untuk menyampaikan kepada raja untuk melepaskannya. Permintaan itu disampaikan Yusuf setelah menafsirkan mimpi penjaga gerbang. Namun, pesan Yusuf untuk raja telah lama terlupakan. Sungguh malu penjaga gerbang itu kepada Yusuf. Tak kuasa ia menghadap Yusuf untuk meminta maaf. Namun raja yakin, Yusuf akan memaafkan penjaga gerbang. Saat bertemu dengan Yusuf, penjaga gerbang langsung bersujud dan meminta maaf atas kelalaiannya. Yusuf memaafkan penjaga gerbang itu. Yusuf meyakini bahwa kelalaian adalah hal di luar kuasa seorang manusia. Penjaga gerbang merasa tidak mampu melakukan amanah yang diberikan padanya. Karena itulah ia benar-benar merasa bersalah, meski ia tahu ia tak sengaja. Besar rasa malu yang ditanggungnya saat mengingat Yusuf.

Mengakui kesalahan adalah hal mudah namun terasa berat untuk dilakukan. Itu karena selalu dikaitkan dengan harga diri dan perasaan selalu benar. Bila memang salah namun tetap merasa benar, itulah wujud kesombongan diri. Saat mendapat permintaan maaf namun enggan memaafkan atau mau memaafkan karena merasa dirinya yang benar, juga wujud kesombongan diri.

Ketaatan berikutnya adalah berempati yang terdapat pada $\mathrm{P}^{\mathrm{XII}} \mathrm{K}$ bait ke-22 sampai 23. Setelah mengungkap makna mimpi raja, 
Yusuf dibebaskan namun ditolak. Yusuf tidak mau keluar penjara jika tahanan lain tidak ikut dibebaskan. Hal ini juga dilakukan oleh Nabi Muhammad. Tidak ingin Nabi Muhammad menginjakkan kaki ke surga bila seluruh umatnya yang ada dalam neraka tidak ikut bersamanya naik ke surga.

Sikap tersebut bukan wujud dari kesombongan diri namun perasaan empati. Berempati atas rasa yang ditanggung oleh orang lain di sekitarnya. Empati juga wujud dari sikap welas asih kepada sesama. Karena rasa yang dialami oleh orang lain bisa dirasakan dan seakan-akan menempati posisi orang tersebut. Orang Jawa menyebut dengan istilah tepo sliro. Inilah wujud habluminannas yang harus diperhatikan.

Pada kategori ketaatan manusia terhadap Tuhan, berupa jujur, bersyukur, berbuat baik di dunia, beribadah, tidak memuji diri sendiri, bertobat, bertutur kata baik, mengakui kesalahan dan memaafkan, serta berempati, termasuk ke dalam religious practice (the ritualistic dimension) atau dimensi praktis. Dimensi yang sudah menunjukkan sikap manusia melalui ibadah yang dilakukan. Ibadah yang dimaksud tidak terbatas pada ritual keagamaan yang berlangsung di tempat ibadah, namun juga melakukan ajaran-ajaran agama yang nilainya adalah sama dengan ibadah. Sementara pengetahuan yang dimiliki macan (pada wujud kejujuran) tentang sebab-akibat berdusta termasuk ke dalam religious knowledge (the intellectual dimension atau dimensi pengetahuan. Macan tahu bahwa ketika ia tidak jujur akan ada ganjaran dari Tuhan untuknya. Ini sebuah pengetahuan yang sampai kini dapat dipelajari dan diamalkan oleh manusia untuk selalu jujur dalam hal apapun yang dijalaninya.

\section{4) Kepasrahan Manusia terhadap Tuhan}

Ajaran kepasrahan manusia terhadap Tuhan termuat dalam $\mathrm{P}^{\mathrm{I}} \mathrm{K}$ bait ke 45-46.

Anêngakêna rumehin / sabdaning Yang kocapa / adhawuhing Ya'kub age / mulane sira tan asêrah/ sira datan pêrcaya / saking ing pangraksaningsun / kaliwat kasilib ira // Wus angrasa Ya'kub iki / yen luput tumulya tobat / anêlangseng jêro dêriyane / kaluputaning wêncana / karo enggala tobat / dening tan asêrah Yang Agung / pijêr amèngêting anak //

Tinggalkanlah sejenak / dikisahkan Tuhan telah bersabda / Dia berkata kepada Yakub / disebabkan kau tiada mau berserah diri / kau tiada percaya / atas penjagaanku terhadap Yusuf / kau kelewat lupa diri // Yakub telah merasa / jika ia salah lalu bersegera tobat / menderita di lubuk hatinya / telah salah dalam berucap kata / hingga bersegeralah ia tobat / karena tiada berserah diri kepada Tuhan / hanya selalu teringat akan anaknya //

$\mathrm{P}^{\mathrm{I}} \mathrm{K}$ bait ke-73

Kocapa Yusup anênggih / tinibakêning têlaga / binuwanging kêdhong nyang wong / lumêmpat sarwi tah sira / sidhakêp mêngkul dhadha / mênggah marsah Nabi Yusup / sarwi angudud ambêkan //

Dikisahkan sang Nabi Yusup / dijatuhkan ke dalam telaga / dilemparkan ke dalam jeram / maka melompatlah ia sambil / bersedekap memeluk dada / teguh berserah diri sang Nabi Yusup / sambil menarik napas //

Pada bait ke-60 sampai 64 yang menceritakan kisah Nabi Yusuf yang hendak dibunuh oleh kesebelas saudaranya. Semua saudara siap menghunuskan pedang, betapa sedih hati Yusuf namun ia teringat bahwa sikap semua saudara Yusuf adalah isyarat dari Tuhan. Yusuf selama ini terlalu menggantungkan diri pada saudarasaudaranya tanpa bersandar pada Tuhan.

Pada bait ke-75 sampai 76 diceritakan tentang pertemuan Yusuf dengan pertapa yang berada dalam telaga. Pertapa itu berkata jika semua yang telah menimpa 
Yusuf adalah kehendak Tuhan. Semua tindak laku kesebelas saudara Yusuf telah ditakdirkan Tuhan bahkan Yusuf berada dalam telaga pun adalah berkat doa sang pertapa agar pertapa dipertemukan dengan Yusuf.

Keempat data tersebut berisi ajaran untuk bersikap pasrah. Kekhawatiran, ketakutan, kecemasan, serta terlalu mengandalkan diri sendiri maupun orang lain merupakan tanda bahwa tidak menyandarkan diri kepada Tuhan. Sifat pasrah dan menyerahkan diri menurut Khalidi and Syam (2017:432) bukan berarti putus asa dan menyalahkan Tuhan. Sifat pasrah atau tawakal merupakan salah satu cara manusia meminta kepada Pencipta agar semua masalah yang sedang terjadi dapat terselesaikan secara baik.

Jika manusia menanamkan sikap tawakal, dan mampu menahan sakit diri maupun hati (hawa nafsu dan iri), maka akan memperkuat iman. Apabila manusia senantiasa nrima dan pasrah, maka hidup akan terasa tenang. Manusia harus berani menghadapi kematian dan menerima kenyataan dengan cara menerapkan sikap tersebut (tawakal dan nrima) karena hal tersebut (kematian dan kenyataan) merupakan kehendak Allah (Harsena \& Holi1, 2018:701).

Kategori ini termasuk ke dalam religious practice (the ritualistic dimension) atau dimensi praktis. Pasrah adalah sikap yang dilandasi keyakinan. Ini berarti, pasrah adalah buah dari kepercayaan atau keimanan terhadap Tuhan.

\subsection{Relevansi dengan Kehidupan di Era Disruptif}

Di awal dijelaskan bahwa perkembangan zaman yang begitu pesat di era disruptif berpeluang menyadarkan manusia terhadap hak-hak kemanusiaan namun juga memungkinkan tergesernya banyak tatanan nilai-nilai sosial kemasyarakatan. Peluang penyadaran manusia terhadap hak kemanusiaan merupakan hal yang sangat baik. Ini menjadi keuntungan adanya sharing of information yang sudah menjadi budaya modern dewasa ini. Masyarakat bisa lebih cepat tahu dan paham akan isu-isu kemanusiaan dan akan lebih cepat terpantik untuk ikut serta dalam upaya penegakan hak-hak kemanusiaan. Di sisi lain, kemungkinan tergesernya tatanan nilai-nilai sosial juga perlu mendapat perhatian. Menjadikan manusia sebagai tujuan tertinggi dalam praktik interaksional di pelbagai bidang adalah hal yang dapat dilakukan. Hal ini guna mencapai keutuhan tatanan nilai sosial dengan menjadikan common values sebagai modal sosialnya.

Sikap yang terus menjadikan manusia sebagai tujuan tertinggi dalam praktik interaksional kehidupan adalah wujud pengaplikasian nilai religiositas. Maka dalam hal ini, nilai-nilai religiositas pada PK sangat relevan terhadap kebutuhan manusia di era disruptif karena PK berisi ajaran untuk senantiasa beriman, taat, dan bertakwa kepada Tuhan. Ajaran tersebut adalah pedoman manusia menjalani kehidupan sebagai makluk ciptaan Tuhan.

Dengan kesadaran yang dimiliki manusia bahwa apapun yang dilakukan di dunia ini akan dipertanggungjawabkan di hari akhir, bahwa semua yang dimiliki manusia di dunia ini sebenarnya adalah titipan Tuhan, maka manusia tidak pantas untuk menyombongkan diri. Keyakinan bahwa sikap sabar akan menyelamatkan manusia di setiap musibah, serta kepercayaan bahwa Tuhan akan selalu tahu apa yang manusia lakukan di dunia ini dan segala perbuatan mendapat ganjaran yang sesuai. Maka keyakinan-keyakinan inilah menjadi pengontrol laku hidup manusia di dunia yang kemudian juga sebagai pengontrol tatanan sosial di kemasyarakatan. Ketika tatanan nilai-nilai sosial terkontrol, dampak era disruptif akan menjadi tidak berarti.

\section{Kesimpulan}

Fungsi sastra daerah sebagai penyebar ajaran agama, salah satunya dalam wujud LYB. Hail penelitian menunjukkan terdapat empat kelompok nilai perwujudan hubungan manusia dengan Tuhan, yaitu 1) keimanan 
terhadap Tuhan, 2) keteringatan manusia terhadap sifat Tuhan, 3) ketaatan manusia terhadap Tuhan dan 4) kepasrahan manusia terhadap Tuhan. Dari empat kelompok nilai religiositas tersebut terdapat empat dimensi religiositas 1) dimensi praktis (religious practice) 2) dimensi ideologis (ideological dimension) 3) dimensi pengetahuan (intellectual dimension, dan 4) dimensi perasaan (experiental dimension).

Nilai religiositas tidak hanya untuk diketahui namun juga diamalkan dalam kehidupan sehari-hari. Nilai religiositas menjadi pegangan manusia dalam menjalani kehidupan. Dampak-dampak era disruptif sebagai hasil kemajuan dan perkembangan zaman, tidak akan berarti manakala manusia mengamalkan ajaran-ajaran Tuhan dalam kehidupannya.

Penelitian ini sangat terbatas. Banyak pupuh lain dalam LYB yang belum diteliti. Peneliti berharap penelitian selanjutnya dapat mengkaji LYB secara lebih komprehensif dan tuntas sehingga fungsi LYB sebagai penyebar ajaran agama Islam tidak berhenti pada pembacaan dan pemahaman melalui hasil penelitian, namun juga pada dibacakannya kembali LYB oleh orang tua kepada anakanaknya. Penanaman pemahaman ajaranajaran agama sejak dini mutlak adanya. Demi mempersiapkan pribadi tangguh moral dan spiritual dalam menghadapi arus perubahan zaman.

\section{Daftar Pustaka}

Bakry, M. (2016). Nilai-Nilai Religiusitas Adat Mo Me'ati pada Masyarakat Kota Gorontalo (Replika Islam Nusantara) Jurnal Al-Ulum, 16(1), 185-207. Retrieved from https://jurnal.iaingorontalo.ac.id/inde x.php/au/article/view/162/134

Endraswara, S. (2018). Falsafah Hidup Jawa. Yogyakarta: Cakrawala.

Estriana, D. P. (2017). Sejarah Manuskrip Lontar Yusuf Sebagai Media Dakwah Masyarakat Osing Banyuwangi. (Sarjana Skripsi), Universitas Islam Sultan Agung, Semarang, Semarang.
Retrieved

from http://repository.unissula.ac.id/8826/

Harsena, D. S., \& Holil, M. (2018). Sikap Ngelmu pada Teks Wedharan Wewadining Bawana Paper presented at the INUSHARTS (International Young Scholars Symposium on Humanities and Arts) Depok.

Indiarti, W. (2018). Lontar Yusup Banyuwangi: Teks PegonTransliterasi-Terjemahan. Yogyakarta: Elmatera.

Khalidi, M. W. A., \& Syam, H. M. (2017). Representasi Nilai-Nilai Moral dalam Lirik Lagu Doda Idi (Studi Semiotik terhadap Lirik Lagu Doda Idi dalam Album Nyawoung). Jurnal ilmiah mahasiswa FISIP Unsyiah, 2(4), 417428. Retrieved from http://www.jim.unsyiah.ac.id/FISIP/ article/view/5522/2631

Komarudin, D. (2017). Nilai Religiusitas Sufistik Dunia Hingga Indonesia: Suatu Kajian Sosial. Syifa Al-Qulub, 2(1), 56-70. Retrieved from http://digilib.uinsgd.ac.id/22068/1/K ARYA\%20ILMIAH\%20NO.\%205.p $\underline{\mathrm{df}}$

Maslikatin, T. (2012). Kerudung Santet Gandrung Dialektika Sastra dan Tradisi Subkultur Masyarakat Using Banyuwangi Paper presented at the Konferensi Internasional Kesusastraan XXII UNY-HISKI: "The Role of Literature in Enhancing Humanity and National Identity", Yogyakarta.

Ohoitimur, J. (2018). Disrupsi: Tantangan Bagi Perkembangan Ilmu Pengetahuan dan Peluang Bagi Lembaga Pendidikan Tinggi Respons, 23(2), 143-166. Retrieved from

http://ejournal.atmajaya.ac.id/index.p $\mathrm{hp} / \mathrm{response/article/view/553/216}$ 
Pora, S. (2014). Tinjauan Filosofis Kearifan Lokal Sastra Lisan Ternate. Jurnal Uniera, 3(1), 112-121. Retrieved from

https://journal.uniera.ac.id/jview/69

Rofiq, A. A., Degeng, I. N. S., Hidayah, N., \& Atmoko, A. (2016). Nilai-Nilai Budaya Suku Using Banyuwangi dalam Kitab Lontar Yusuf dan Aplikasinya pada Konseling. Paper presented at the Kebhinekaan dan Masa Depan Indonesia: Peran Ilmu Sosial dalam Masyarakat, Malang.

Sholekhah, F. (2019). Pendidikan Karakter melalui Revolusi Mental di Era Disruptif. Modeling: Jurnal Program Studi PGMI, 6(1), 64-88. doi:https://doi.org/10.36835/modelin g.v6i1.343

Subadiyono. (1999). Nilai Budaya dalam Puisi Rakyat Panesak. Jakarta: Pusat Pembinaan dan Pengembangan Bahasa.

Sulaiman, A. (2016). Memahami Teori Konstruksi Sosial Peter L. Berger. Society, 4(1), 15-22. doi:https://dx.doi.org/10.33019/socie ty.v4i1.32

Supanggih, E. A. M., Ferdyani, C., \& Dwi, A. A. (2017). Nilai Religiositas dalam Tembang "Tak Lela-Lela Ledhung". JURNAL SATWIKA, 1(2), 20-28. doi:https://doi.org/10.22219/SATWI KA.Vol1.No2.20-28

Thoyyibah, N. (2016). Nilai-Nilai Pendidikan Keimanan dan Ketaqwaan (Studi Analisis Novel Pesantren Impian Karya Asma Nadia). (Sarjana Skripsi), Universitas Islam Negeri Walisongo, Semarang. Retrieved from http://eprints.walisongo.ac.id/id/epri $\underline{\text { nt/6023 }}$

Tresna, G., Maryana, M., Fatimah, N., \& Priyanto, A. (2018). Nilai
Religiusitas dalam Tinjauan Sajak "Potret Keluarga" Karya WS Rendra. Parole (Jurnal Pendidikan Bahasa dan Sastra Indonesia), 1(2), 207-216. Retrieved from https://journal.ikipsiliwangi.ac.id/ind ex.php/parole/article/view/216/pdf

Turahmat, T. (2019). Tatanan Sosial Masyarakat Jawa dalam Puisi Bolong Karya Joko Pinurbo. JSI: Jurnal Sastra Indonesia, 8(2), 88-93. doi:https://doi.org/10.15294/jsi.v8i2. $\underline{33714}$ 